\title{
Teaching Lab-based Courses Remotely: Approaches, Technologies, Challenges, and Ethical Issues
}

\author{
Zainab S. Attarbashi ${ }^{1 *}$, Aisha Hassan Abdalla Hashim², Mustafa Ali Abuzaraida ${ }^{3}$, \\ Othman Omran Khalifa ${ }^{2}$ and Manar Mustafa ${ }^{4}$ \\ ${ }^{1}$ Kulliyyah of Communication \& Information Technology, \\ International Islamic University Malaysia, Kuala Lumpur, Malaysia \\ ${ }^{2}$ ECE Department, Kulliyyah of Engineering, \\ International Islamic University Malaysia, Kuala Lumpur, Malaysia \\ ${ }^{3}$ Computer Science Department, Faculty of Information Technology, \\ Misurata University, Libya \\ ${ }^{4}$ Kulliyyah of Islamic Revealed Knowledge (IRKHS), \\ International Islamic University Malaysia, Kuala Lumpur, Malaysia \\ *Corresponding Author: zainab48@hotmail.com
}

\begin{abstract}
Online learning has gained substantial traction since the popularization of Massive Open Online Courses (MOOCs) over the last decade. After the dawn of the Covid-19 pandemic, online learning has become an indispensable mode of modern-day education. All educational institutions around the world are now compelled to switch to online classes as a physically safer and more flexible option for teaching and learning during the pandemic. Although many studies have examined the effectiveness of this online T\&L mode, almost no attention has been paid to the use of virtual laboratories, which are an important means of teaching practical skills and complicated theories for science and engineering subjects. Like other online methods that have their particular advantages and disadvantages, the utility of virtual laboratories is detracted by the fact that they lack some of the qualities present in the actual experiments seen in traditional learning classrooms. In particular, virtual labs are not as effective as authentic lab experiments in developing soft skills that are typically acquired from students' teamwork activities, in addition to lacking the ability to assess the various levels of knowledge acquisition, content mastery and student attention in class. Hence, the aim of this paper is to address these issues about the utility and drawbacks of virtual labs in achieving the long-term goals and learning outcomes of STEM education. In addressing these issues, the paper highlights the varying technologies, such as gaming and virtual reality, used by different educational institutions as substitutes for physical engineering laboratories. The final section of the paper discusses some of the ethical issues related to online learning for science and engineering subjects.
\end{abstract}

Keywords: MOOCs, online learning, STEM, online ethics, virtual laboratories, virtual reality 


\section{INTRODUCTION}

Properly designed e-learning has the capacity to provide rich learning environments and inspiring learning experiences for students and is already a major driver for 21 st century education, especially after the COVID-19 pandemic. However, in the engineering field, the physical distance and the lack of face-to-face interaction in classes conducted online complicate the learning process for some courses and subject matter. This is especially true with engineering courses and subjects that contain technical elements, where theoretically oriented teaching models lack the ability to transfer knowledge and specialized skills effectively (Loro et al., 2018). Since the rise of Massive Open Online Courses (MOOCs), engineering instructors have faced a new challenge as they transitioned to online learning. In engineering education, it is critically important that the theoretical knowledge conveyed to students in the classroom be effectively supplemented with practical experience gained through laboratory experiments. Due to the challenging nature of their specialization, engineering students need to have interactive, hands-on learning opportunities to support their theoretical classroom learning (Barak \& Usher, 2019). The provision of such practical activities became a real challenge after the break of the COVID-19 pandemic in March 2020, forcing colleges and universities around the world to quickly transition to online learning (Ferri et al., 2020). Generally, although it seems that many educational institutions are effectively running their classes online, one troubling issue remains unaddressed. In the face of the mounting need to offer and continue with online learning, universities are confronted with the issue of students' not having good access to the Internet and computing resources and with the issue of lecturers' lacking the technical skills to effectively moderate online classes. The presence of these issues suggests that students and lecturers may not be fully ready, technically, to handle online teaching and learning, hence creating some long-term impacts that should be paid attention to. Therefore, the long-term impacts of this sudden, unexpected change of instructional mode should be systematically investigated.

Technically and pedagogically, delivering certain subjects is inherently more challenging and difficult than others. Science, engineering, and technology, for example, should impart theoretical knowledge via practical hands-on learning activities. This often takes place through traditional hands-on laboratory experiments where active student engagement is the most effective means of ensuring mastery. With online education, effective methods of experiential learning in virtual and remote laboratories must be carefully designed and developed to support self-directed student learning activities through synchronous or asynchronous delivery. While engineering lab work can be particularly difficult to adapt and transform to an online learning environment, some instructors are finding creative ways to replicate these activities virtually (Abramovitch, 2019).

In this paper, we present the different approaches to teaching engineering labs implemented by different learning institutions. The following section covers the various ways in which institutions and instructors have adapted virtual reality and gaming technology to accurately simulate experimental labs. In the subsequent section, we discuss some ethical issues related to online learning. 


\section{Approaches to Lab-Based Online Courses}

Due to universities' Covid-19 guidelines and standards of operation, many laboratories have migrated wholly or partially to online platforms (Grodotzki et al., 2018; Sanchez-Herrera et al., 2019; Torre, 2019b), doing away with the hands-on portion of classroom learning. Recent research (e.g., Loro et al., 2018; Bose, 2013; Ngoyi, 2013; Ray et al., 2012) shows that several institutions have even established their own remote and virtual laboratories to support lifelong learning and students' autonomous learning activities in various engineering disciplines, including electronics and microelectronics, electrical drives and power electronics (Viegas et al., 2018; Wang et al., 2018), manufacturing (Grodotzki et al., 2018), biology (Lunsford et al., 2013) and biotechnology (Barak \& Usher, 2019), control (Torre et al., 2019a), and networking (Louhab et al., 2019).

Several difficulties associated with e-learning courses have driven researchers to look into these issues from the perspectives of students and faculty (Ferri et al., 2020; Bose, 2013; Wang et al., 2018; Karimipour et al., 2020; Bandaya et al., 2014; Heintz et al., 2015; Vate-U-Lan, 2008). In general, as explained by Vate-U-Lan (2008), in comparison to face-to-face lectures, it is more difficult to track which and how many students are actually participating in online meetings, and it is even more difficult to engage with them online. Additionally, there are many difficulties that arise from the use of virtual classes or labs where the infrastructure is not quite ready for this sudden move to online learning. According to Ngoyi (2013), teachers and administrators both agree that the benefits of virtual labs for student learning are many and they include hands-on learning, flexibility, and convenience. The benefits notwithstanding, the following challenges come with virtual labs, as mentioned by administrators, i.e., constant technological changes, insufficient teacher preparation for virtual teaching-resulting in extra training for them; frequent failure of laboratory equipment and software; and instructors' resistance to curriculum change. The issue of the lack of appropriate lab facilities in many colleges was also addressed by Bose (2013), in addition to the limited number of well-trained lecturers who can make remote experimentation possible (Viegas et al., 2018; König et al., 2020).

On the students' side, the most significant challenge is the lack of student motivation and interest in various course activities and materials (Bandaya et al., 2014). In addition, there is also a lack of interaction with other students during online labs, and this is an important concern as engineering students are encouraged to work in small teams on projects involving real-world industrial phenomena. The ability to work effectively as an engaged member of a team is among the topmost important behavior attributes needed for engineers (Kroisandt, 2018), yet this component cannot be truly felt and implemented in online learning. To meet industry needs, teamwork is studied extensively in engineering education. Karimipour (2020) found that the use of virtual reality may have some benefit for teamwork in the lab, but it is less efficient in developing students' creativity, innovation skills, and ability to learn from one another. Additionally, the study found minimal improvement in students' cognitive outcomes compared to traditional class settings. 
According to Barak and Usher (2019), the absence of physical interaction in online learning may lead to low levels of engagement. Another point of concern is the inability of online courses to provide students with personalized learning support and guidance from instructors. Due to the lack of face-to-face interaction, online learners cannot gauge the nonverbal behavior of their peers, i.e., the postures, gestures, body movements, and facial expressions of other learners. Such non-verbal behaviors are recognized as a crucial source for gathering information about the effectiveness of engineering student teams. The absence of such clear communication in an online platform could result in misunderstandings between online learners and their peers, as well as in the misinterpretation of ideas.

Virtual labs are online platforms where learners can gain the experience of practical experimentation without having to be physically present (Ray et al., 2012). To create interactive content, virtual labs use computerized simulations, models, animations, films, and other instructional technologies. A good virtual lab requires the use of a simulation software that can create realistic virtual environments that give students an idea of how experiments would be carried out in actual labs. Virtual labs can ensure that users always have access to practical experiments, regardless of their geographical location (Loro et al., 2018). Despite the affordances of virtual labs, they may still be insufficient for real learning as many details about engineering content can only be comprehended through practical experience. In this case, the knowledge gained by students is often limited by the capabilities of the simulation software being used. The experimental procedures in real laboratories go beyond simple step-by-step protocols, and the overall results of the experiment are frequently dependent on the performer's technical skills, which cannot be acquired from online learning alone. A case in point is the ELLI2 project presented by Grodotzki et al. (2018), which had to be improved with the addition of new processes and technologies such as Augmented Reality and Additive Manufacturing.

Some online classes have opted to preserve the hands-on component of their respective courses by purchasing tools or kits for all students to use at home (ABET, 2016-2017). An advantage of this method is it enables students to repeat and adjust settings, modify parameters, and perform as many tests as they need to without being constrained by a scheduled laboratory. Additionally, students have more time and flexibility to be creative and ask thoughtful questions. In terms of cost, take-home options might range from very cheap to exorbitant when compared to the cost of providing robust laboratory equipment, laboratory space, and support employees-depending on the nature of the subject. Another factor to consider in such a solution is the availability of high-quality support services to prevent the need for constant assistance. Table 1 summarizes the different approaches used in universities around the world, along with the drawbacks of each approach. 
Table 1

Summary of Different Approaches Employed During the Covid-19 Pandemic

\begin{tabular}{|c|c|c|}
\hline Type of Approach & Applicability & Drawbacks \\
\hline Lab kits at home & $\begin{array}{l}\text { Expensive as lab } \\
\text { kits must be sent to } \\
\text { every student. } \\
\text { - Not all labs can be } \\
\text { done with small and } \\
\text { affordable tools }\end{array}$ & $\begin{array}{l}\text { - Lack of technical support } \\
\text { - Instructors need to be creative enough to } \\
\text { deliver the lab effectively to allow students } \\
\text { - to do lab work later on their own } \\
\text { - Lack of properly developed teamwork skills } \\
\text { - Difficulty to get technical support from the } \\
\text { instructor during lab or tool failure } \\
\text { - Lack of student motivation } \\
\frac{0}{60} \text { - Lack of personal support } \\
\frac{0}{0} \text { - No interaction among students } \\
\text { - Misinterpretation of non-verbal behaviors }\end{array}$ \\
\hline Virtual Lab & $\begin{array}{l}\text { - Flexible--students } \\
\text { are not limited to } \\
\text { specific } \\
\text { geographical areas } \\
\text { - Best option for } \\
\text { MOOCs } \\
\text { - Tools, simulations, } \\
\text { software, and VR } \\
\text { applications should } \\
\text { be programmed } \\
\text { - Requires technical } \\
\text { training for } \\
\text { instructors } \\
\text { - Technical and } \\
\text { network } \\
\text { infrastructure must } \\
\text { be ready }\end{array}$ & $\begin{array}{l}\text { - Lack of student engagement and } \\
\text { participation } \\
\text { - No hands-on learning } \\
\text { - Students may not develop creativity as all } \\
\text { - } \begin{array}{l}\text { problems and solutions are already pre- } \\
\text { - }\end{array} \text { Programmed } \\
\text { - Susceptible to lab, tool, equipment and } \\
\text { other technical failures }\end{array}$ \\
\hline Traditional classes & $\begin{array}{l}\text { - Not possible in } \\
\text { areas heavily } \\
\text { affected by a } \\
\text { pandemic } \\
\text { - Effective in } \\
\text { situations where } \\
\text { small groups of } \\
\text { students can } \\
\text { physically come to } \\
\text { labs } \\
\text { - Not possible for } \\
\text { MOOCs }\end{array}$ & $\begin{array}{l}\text { - Limited to geographical areas } \\
\text { - Increased health risks during a pandemic } \\
\text { - Lab instructors must be physically present } \\
\text { for every session } \\
\text { - Not possible for massive classes }\end{array}$ \\
\hline
\end{tabular}


Table 1 (continued)

\begin{tabular}{lll}
\hline Type of Approach & \multicolumn{1}{c}{ Applicability } & \multicolumn{1}{c}{ Drawbacks } \\
\hline & - $\begin{array}{l}\text { Teaching can be } \\
\text { done synchronously } \\
\text { or asynchronously }\end{array}$ & \\
& - Fosters teamwork \\
& spirit among & - Limited to geographical areas \\
students & - Lack of the required infrastructure \\
Blended Learning & - Allows students to & - Dearth of instructors having expertise in \\
& manage their own & technological advancements. \\
& time & Needs precise efforts, good budgets, and \\
& - Students can & highly qualified instructors for its successful \\
& interact with each \\
other either in the & implementation \\
physical or virtual & \\
mode & \\
\hline
\end{tabular}

Some universities have managed to implement blended learning despite the challenges of the pandemic (Nijakowski et al., 2021; Gupta \& Gupta, 2020; Fadillah et al., 2020; Orji, 2021), where theoretical knowledge is imparted remotely via an online learning portal and Teams communicator, while practical classes are conducted with the participation of patients in the appropriate sanitary regime. Among the advantages of this learning mode, according to Nijakowski et al. (2021), is that it makes learning more efficient as students are allowed to learn at their own individual pace. However, its major disadvantage is the absence of social contact between the parties involved in the learning process.

\section{Technologies Used in Online Classes}

In this section, some of the most frequently used technologies in delivering online learning are described. There are an unlimited number of available applications and ICT tools that have been used for remote teaching. Faculty and educational developers in higher education face a huge challenge in determining which online learning technology is most suited to serve their specific teaching objectives and give the best learning possibilities for students. A substantial amount of literature on e-learning technologies and how they are applied in education has been written in recent years (Annemieke et al., 2021; Vargo et al., 2020).

The use of ICT and instructional technology during the COVID-19 pandemic has helped to sustain education for the masses through the provision of synchronous and asynchronous online instruction in a physically safe context. Such technologies have enabled schoolteachers and university instructors to create virtual teaching and learning environments on various platforms, offer pedagogically innovative approaches to facilitate learning via the online mode, and engage struggling students in fun and meaningful activities (Vargo et al., 2020). Faculty's use of instructional technology can be limited by the university's lack of resources or poor 
Internet connectivity in the country. In this event, open-source tools-such as Google Meet and Moodle (El-Seoud, 2014), cloud storage for keeping documents, and free social media platforms - are helpful as they reduce operating costs (Arkorful \& Abaidoo, 2020). Table 2 summarizes some of the technologies generally used in remote learning.

\begin{tabular}{ll}
$\begin{array}{l}\text { Table } 2 \\
\text { Categories of Technology Used for Remote Learning }\end{array}$ \\
\hline \multicolumn{1}{c}{ Technology } & \multicolumn{1}{c}{ Tool Examples } \\
\hline Hardware & $\begin{array}{l}\text { Webcam-enabled computers, Mobile } \\
\text { devices }\end{array}$ \\
\hline Assessment and Survey tools & $\begin{array}{l}\text { Survey Monkey, Google Forms, } \\
\text { Survey Planet, ExamBuilder, HubSpot } \\
\text { Forms, ProctorU }\end{array}$ \\
\hline Asynchronous & Whatsapp, Telegram, Email, online \\
Communication & discussion forums, e-learning portal \\
\hline $\begin{array}{l}\text { Management and } \\
\text { Administration Tools }\end{array}$ & $\begin{array}{l}\text { Turnitin, Eduflex, Exam4u, } \\
\text { TrackMyClass, WorkZone } \\
\text { Photosharing }\end{array}$ \\
\hline Flickr, Google Photos, Apple iCloud \\
\hline Shared Documents & $\begin{array}{l}\text { Dropbox. Google Drive, iCloud Drive. } \\
\text { SlideShare }\end{array}$ \\
\hline Social Networking & $\begin{array}{l}\text { Facebook, Telegram, Instagram, } \\
\text { LinkedIn }\end{array}$ \\
\hline Synchronous Communication & $\begin{array}{l}\text { Zoom, Cisco Webex, Google } \\
\text { Hangouts, Google Meet, } \\
\text { BigBlueButton }\end{array}$ \\
\hline Virtual Worlds & $\begin{array}{l}\text { Second Life (SL), Virtual Graffiti, } \\
\text { eSimulations }\end{array}$ \\
\hline
\end{tabular}

\section{Virtual Reality Technologies in Online Labs}

In the education sector, virtual reality (VR) has emerged as a new technical instrument. Several studies have shown that VR is an effective tool in a variety of teaching and learning situations (ABET, 2016-2017) and that it benefits learners by improving their understanding of course content, in addition to helping instructors manage the learning process (Kroisandt, 2018). Since it can simulate hi-fidelity engineering experiments in their authentic environments, VR has been used to improve the practical, hands-on learning component in engineering courses. Many subjects, including the sciences (Gupta \& Gupta, 2012; Markowitz et al., 2018; Brown et al., 2020), languages (Enkin et al., 2021; Xie et al., 2019), chemistry (Abdinejad et al., 2020; Klingenberg et al., 2020), and mathematics (Cai et al., 2019), have yielded improved learning outcomes among students due to the use of VR.

In several recent studies, the effectiveness of VR technology was evaluated and compared to that of standard teaching strategies in several content areas. An intervention combining 
fundamental chemical processes and 3D animations as an augmented reality tool, called ARchemy, was developed in the field of chemistry (Abdinejad et al., 2020). The research was carried out on undergraduate organic chemistry students in their second and third year of study. A survey was run to collect student comments on the efficiency and effectiveness of these tools. The analysis of students' comments revealed overwhelmingly positive feedback about the technology's usefulness in boosting their understanding. Based on students' feedback, it became apparent that VR could help overcome the shortcomings of traditional learning methods.

Klingenberg et al. (2020) conducted a study in the same educational environment to examine the effects of conducting chemistry classes using immersive virtual reality (IVR) with a head-mounted display (HMD), comparing them to lessons using desktop virtual reality (DVR). The results indicated that students who learned chemistry with the DVR/IVR technology did not improve in terms of perceived motivation, enjoyment, or online presence, while those who used other learning media showed notable differences in the three constructs, with the students preferring IVR to the DVR/IVR.

Another study by Nijakowski et al. (2021) emphasized the need for educational stakeholders to consider how traditional learning approaches could be combined with VR technologies after qualitatively examining students' impressions of learning science via VR. Similarly, Artun et al. (2021) examined the impact of a virtual reality (VR) rendition of enriching laboratory activities on the science process skills of Turkish pre-service science teachers who served as the experimental subjects. The teachers were assigned to the treatment and control groups with 24 and 30 subjects, respectively, in each group. After a 6-week intervention, the treatment group outperformed the control group in the posttest scores. Another study (i.e., Beyoglu et al., 2020) looked at the effects of integrated VR applications on students' motivation to learn science. Forty-two primary school students took part in the study for eight weeks. The findings of the study revealed that using VR to motivate students to learn science was a pedagogically correct decision.

VR tools were created to assist in the teaching of middle school science subjects in Liu et al. (2020). The study's goal was to look into the effects of virtual reality lectures on learning outcomes. A pretest and posttest were used to assess students' academic achievements, while a questionnaire was used to assess students' technological acceptability and involvement with the learning process. In this study, 90 students were randomly assigned to the control and experimental groups in two courses. In comparison to the control group, the experimental group achieved substantially higher engagement scores and greater learning progress, which implied the effectiveness of VR as a technology for academic learning.

Virtual Reality has also been applied in several fields of education, such as linguistics, as an alternative method for teaching languages. Enkin et al. (2021) carried out a study in which an effective virtual reality linguistic learning lab was created to teach speaking skills in an advanced-level Russian language course. The findings revealed that utilizing VR to teach Russian increased student motivation, deep learning, focus, and creativity. Another study by Beyoglu (2020) looked into the use of virtual reality tools by foreign college students learning 
Chinese. According to the results, the VR technology provided an accurate context for learning the Chinese language. A study by Liu et al. (2020) was conducted in the mathematical and statistical fields by integrating three mobile VR-based applications into a sequence of probability lectures for 68 junior high school students. The study's goal was to see how VRbased learning applications affected the learning process. The findings revealed that VR-based applications on mobile platforms could work together to achieve a subject's stipulated learning outcomes.

On the engineering side, a pretest-posttest quasi-experimental study was conducted by Chang (2020) involving Taiwanese high school students to investigate the effects of VR on Engineering Design (ED) in terms of creativity. The results revealed that using VR technologies in ED had a favourable impact on students' ED grades. Ke and Xu (2020) investigated the ability of VR tools to support the learning environment for teacher assistants. A total of 42 chemistry teaching assistants took part in a three-hour teacher training session for the study. After completing the VR course, the results revealed an increase in the participants' teaching knowledge.

\section{Ethical Issues in Online Learning}

In the education sector, virtual reality (VR) has emerged as a new technical instrument. Several studies have shown that VR is an effective tool in a variety of teaching and learning situations (ABET, 2016-2017) and that it benefits learners by improving their understanding of course content, in addition to helping instructors manage the learning process (Kroisandt, 2018). Since it can simulate hi-fidelity engineering experiments in their authentic environments, VR has been used to improve the practical, hands-on learning component in engineering courses. Many subjects, including the sciences (Gupta \& Gupta, 2012; Markowitz et al., 2018; Brown et al., 2020), languages (Enkin et al., 2021; Xie et al., 2019), chemistry (Abdinejad et al., 2020; Klingenberg et al., 2020), and mathematics (Cai et al., 2019), have yielded improved learning outcomes among students due to the use of VR.

Online learning is a term broadly used to describe the process of teaching and learning delivered, assessed, and certified with the aid of online tools anytime and anywhere at the pace and convenience of students. It is based not only on technological tools but also on the process approach. Although there are many advantages of online learning, it also has certain drawbacks, such as the difficulties in assuring academic honesty or detecting academic fraud. Because it is difficult to identify dishonesty in an online environment, students are more tempted to cheat or use covert means to complete assignments. Face-to-face interaction with students can help lecturers to detect inappropriate or unethical behavior, even if it is as subtle as body language.

To minimize dishonesty in online education, it is necessary to have an appropriate variety of assessment methods to deter all forms of academic dishonesty. Examiners should use various methods in the assessment process to ensure the right student is assessed and different accreditation procedures to minimize the chances of academic dishonesty. For instance, the 
assessment can be done through online conferencing, which will ensure that it is the registered student himself/herself who has completed the assessment process, and not someone else. The examiner can use electronic conferencing to verify the image of the student. This technology verifies that the person completing the assessment process is the right person enrolled in the course (Rossiter, 2019).

In online learning, the exam should be time-framed to ensure the student finishes the exercise within the given time. This will ensure greater accountability during the assessment process. Additionally, when conducting an online assessment, the examiner should ensure that all registered students complete the examination at the same time (Palloff, 2009). Due to the widespread commission of academic dishonesty among present day students, we cannot trust that they have been taught traditional values and good morals at home. Institutions must think of ways to produce complete individuals (or "Insan Kamil" in Malay) with proper morals and good conscience.

Researchers have suggested different approaches to preventing and curbing academic dishonesty among students. For example, Haughey (2007) has suggested the following three approaches: first, institutions must seek to develop students who do not have the inclinations to cheat; second, they should prevent dishonesty by identifying and eliminating all opportunities for students to cheat; and third, they should act as policing agents where students guilty of academic dishonesty are apprehended and punished.

In conclusion, when we talk about ethics for online learning, we think of a system of thought by which the online learner can manage their own learning. Therefore, cultivating moral values and good conscience into the learner's psychological realm and personality is the best way to ensure self-restraint and self-governing ethics. 


\section{CONCLUSION}

In the past two years, academia has been compelled to make a dramatic shift from traditional classroom learning to online education as a result of the Covid-19 pandemic. As this paper has pointed out, this decision will have a wide range of long-term consequences for the present generation of university students, specifically for those students studying science and engineering, as their courses are more difficult to teach since they rely significantly on practical experiments to convey the specialized knowledge of the disciplines.

As a result, every educational institution is working on finding solutions to the overwhelming issue of effective online learning in order to improve student engagement and experiential learning and reduce learning loss. We cannot dispute the benefits that virtual learning has brought to students who, for a variety of reasons, are unable to pursue traditional education. But to truly address the appropriateness of online learning for science and engineering courses, longitudinal research must be conducted to help decide if abandoning physical labs would have any long-term negative consequences on students' learning outcomes. Researchers, educational institutions, businesses, the industry and policymakers should participate in such research and collaborate to provide adequate answers to the challenges and teaching and learning difficulties emerging from this pandemic. 


\section{REFERENCES}

Abdinejad, M., Talaie, B., Qorbani, H. S., \& Dalili, S. (2020). Student Perceptions Using Augmented Reality and 3D Visualization Technologies in Chemistry Education. Journal of Science Education and Technology. doi:10.1007/s10956-020-09880-2

Abramovitch, D.Y. (2019). Thoughts on furthering the control education of practicing engineers. IFAC PapersOnLine, 52(9): p. 85-90.

Accreditation Board for Engineering and Technology (ABET) (2016-2017). Criteria for accrediting engineering programs. Baltimore, M.A., Inc.

Arkorful, V., \& Abaidoo, N. (2020). The role of e-learning, the advantages and disadvantages of its adoption in Higher Education. International Journal of Education and Research Vol. 2 No. 12 December 2014

Artun, H., Durukan, A., \& Temur, A. (2020). Effects of virtual reality enriched science laboratory activities on pre-service science teachers' science process skills. Education and Information Technologies. doi:10.1007/s10639-020-10220-5

Bandaya, M.T., \& Janc, T.R. (2014). Applications of e-Learning in engineering education: A case study. Procedia - Social and Behavioral Sciences, 123: p. 406-413.

Barak M. \& Usher M. (2019). The innovation profile of nanotechnology team projects among face-to-face and online learners. Computers and Education, 137: p. 1-11.

Beyoglu, D., Hürsen, Ç., \& Nasiboglu, A. (2020). Use of mixed reality applications in teaching of science. Educ. Inf. Technol. 25(5): 4271-4286.

Bose, R. (2013). Virtual labs project: A paradigm shift in Internet-based remote experimentation. IEEE Access, p. 718-725.

Brown, B., Pérez, G., Ribay, K., Boda, P.A., \& Wilsey, M. (2020). Teaching Culturally Relevant Science in Virtual Reality: "When a Problem Comes, You Can Solve It with Science.” Journal of Science Teacher Education, 1-32. doi:10.1080/1046560x.2020. 1778248

Cai, S., Liu, E., Shen, Y., Liu, C., Li, S., \& Shen, Y. (2019). Probability learning in mathematics using augmented reality: impact on student's learning gains and attitudes. Interactive Learning Environments, 1-14.

Chang, Y. S. (2020). Influence of virtual reality on engineering design creativity. Educational Studies, 1-17.

Craig, A., Coldwell-Neilson, J., Goold, A., \& Beekhuyzen, J. (2012). A Review of E-Learning Technologies: Opportunities for Teaching and Learning. CSEDU 2012 - Proceedings of the 4th International Conference on Computer Supported Education.

El-Seoud, M.S.A., Islam, A.T.F.T., Seddiek, N., El-Khouly, M.M., \& Nosseir, A. (2014). ELearning and Students' Motivation: A Research Study on the Effect of E-Learning on Higher Education. International Journal of Emerging Technologies in Learning (iJET), Vol 9, No 4, pp 20-26 
Enkin, E., Tytarenko, O., \& Kirschling, E. (2021). Integrating and Assessing the Use of a "Makerspace" in a Russian Cultural Studies Course: Utilizing Immersive Virtual Reality and 3D Printing for Project-Based Learning. CALICO Journal, v38 n1 p103-127 2021

Fadillah, A., Nopitasari, D., \& Pradja, B.P. (2020). Blended Learning Model During the Covid19 Pandemic: Analysis of Student's' Mathematical Disposition, JTAM (Jurnal Teori dan Aplikasi Matematika), Vol. 4, No. 2, October 2020, pp. 173-181

Ferri, F., Grifoni, P., \& Guzzo, T. (2020). Online Learning and Emergency Remote Teaching: Opportunities and Challenges in Emergency Situations. Societies, 10(4), 86.

Grodotzki, T.R.O., \& Tekkaya, A.E. (2018). Remote and Virtual Labs for Engineering Education 4.0: Achievements of the ELLI project at the TU Dortmund University. Procedia Manufacturing, 26: p. 1349-1360.

Gupta, S.B., \& Gupta, M. (2020). Technology and E-Learning in Higher Education. International Journal of Advanced Science and Technology, Vol. 29, No. 4, pp. 1320 1325

Haughey, D. J. (2007) Ethical relationships between instructor, learner and institution. Open Learning, 22 (2), pp.139-147.

Heintz, C.E.L.L., Manoli, C., Zacharia, Z., \& Riesen, S.A.N. (2015). A survey on the usage of online labs in science education: Challenges and implications. 2015 IEEE Global Engineering Education Conference (EDUCON), 2015: p. 827-835.

Karimipour, M., Pahlevan Sharif, S., Allen, K.A., \& Naghavi, N. (2020). Virtual reality and augmented reality in education: a systematic review. Abstract from Business, Law and Management at the Post-Pandemic Era, Malaysia.

Ke, F., \& Xu, X. (2020). Virtual reality simulation-based learning of teaching with alternative perspectives taking. British Journal of Educational Technology. doi:10.1111/bjet.12936

Klingenberg, S., Jørgensen, M.L.M., Dandanell, G., Skriver, K., Mottelson, A., \& Makransky, G. (2020). Investigating the effect of teaching as a generative learning strategy when learning through desktop and immersive VR: A media and methods experiment. British Journal of Educational Technology, 51(6), 2115-2138.

König, J., Jäger-Biela, D.J., \& Glutsch, N. (2020). Adapting to online teaching during COVID19 school closure: teacher education and teacher competence effects among early career teachers in Germany. European Journal of Teacher Education, 1-15.

Kroisandt, C.A.a.G. (2018). Opportunities and Challenges with E-Learning Courses in Statistics for Engineering and Computer Science Students. 2018 IEEE World Engineering Education Conference (EDUNINE), p. 1-4.

Liu, R., Wang, L., Lei, J., Wang, Q., \& Ren, Y. (2020). Effects of an immersive virtual realitybased classroom on students' learning performance in science lessons. British Journal of Educational Technology. doi:10.1111/bjet.13028 
Loro, F.G., Losada, P., Gil, R., Rey, A.L., Cristobal, E.S., Molina, C.P., ... Castro, M. (2018). Real Experiments in a MOOC Through Remote Lab VISIR: Challenges, Successes and Limits. Learning With MOOCS (LWMOOCS).

Louhab, F.E., Bahnasse, A., Bensalah, F., Khiat, Y., \& Talea, M. (2019). Towards an E-Lab Solution for Network Assisted Learning. Procedia Computer Science, 155: p. 386-393.

Lunsford, C.L.H.a.E. (2013). Challenges and Opportunities for Learning Biology in DistanceBased Settings. Journal of College Biology Teac, 39(1): p. 27-33.

Markowitz, D.M., Laha, R., Perone, B.P., Pea, R.D., \& Bailenson, J.N. (2018). Immersive Virtual Reality Field Trips Facilitate Learning About Climate Change. Frontiers in Psychology, 9, 1-20. doi:10.3389/fpsyg.2018.02364

Ngoyi, L. (2013). Benefits and Challenges Associated with Using Virtual Laboratories and Solutions to Overcome Them. Virginia Polytechnic Institute and State University.

Nijakowski, K., Lehmann, A., Zdrojewski, J., Nowak, M., \& Surdacka, A. (2021). The Effectiveness of the Blended Learning in Conservative Dentistry with Endodontics on the Basis of the Survey among 4th-Year Students during the COVID-19 Pandemic. International Journal of Environmental Research and Public Health, 18(9), 4555.

Orji, C.T, Anaele, E.A.O., Olelewe, C.J., Kanu, C.C., \& Chukwuone, C.A. (2021). A Critical View on Blended Learning Improvement Strategies in Post-COVID 19. IETE Journal of Education, 20 Aug 2021

Palloff, R. \& P. (2009) Assessing the Online Learner. San Francisco, CA: John Wiley \& Sons.

Ray, S., Koshy, N.R., Reddy, P.J., Srivastava, S. (2012). Virtual Labs in proteomics: New Elearning tools. Journal of Proteomics, 75: p. 2515-2525.

Rossiter, J.A., Jones, B.L., Pope, S., Hedengren, J.D. (2019). Evaluation and Demonstration of Take Home Laboratory Kit. 12th IFAC Symposium on Advances in Control Education. 52(9): p. 56-61.

Sanchez-Herrera, R.M., A.; Márquez, M.; Andújar, J, The Remote Access to Laboratories: A Fully Open Integrated System. IFAC-PapersOnLine, 2019. 52: p. 121-126.

Torre, L., Chacon, J., Chaos, D. (2019). A Master Course on Automatic Control with Remote Labs. IFAC-PapersOnLine, 52(9): p. 48-49

Torre, L., Chaos, D., Dormido, S., \& Sanchez, J. (2019). Using Server-Sent Events for EventBased Control Laboratory Practices in Distance and Blended Learning. 18th European Control Conference (ECC), p. 3053-3058.

Vate-U-Lan, E.D. (2008). Mobile Learning: Major Challenges for Engineering Education. Proceedings: The 38th. Annual Frontiers in Education Conference. Saratoga Springs, NY, USA.

Vargo, D., Zhu, L., Benwell, B., \& Yan, Z. (2020). Digital technology use during COVID -19 pandemic: A rapid review. Human Behavior and Emerging Technologies, 3(1), 13-24. doi:10.1002/hbe 2.242 
Viegas, C., Pavani, A., Lima, N., Marques, A., Pozzo, I., ... Alves, G. (2018). Impact of a remote lab on teaching practices and students learning. Computer \& Education, 126: p. 201-216.

Wang, C. (2018) Connecting Theory to Practice in an Online Introductory Signals and Systems Course Connecting Theory to Practice in an Online Introductory Signals and Systems Course. Proc. Frontiers in Education 2018.

Xie, Y., Ryder, L., \& Chen, Y. (2019). Using Interactive Virtual Reality Tools in an Advanced Chinese Language Class: a Case Study. TechTrends. doi:10.1007/s11528-019-00389-Z 